\title{
TITLE:
}

\section{Reporls from the Field : Mahale, Tanzania : Ntologi Falls??!}

$\operatorname{AUTHOR}(\mathrm{S})$ :

\section{CITATION:}

Reporls from the Field : Mahale, Tanzania : Ntologi Falls??!. Pan Africa News 1995, 2(2): 9-10

ISSUE DATE:

1995-10

URL:

http://hdl.handle.net/2433/143324

\section{RIGHT:}

Copyright (C) Pan Africa News. 


\section{MAHALE, TANZANIA}

\section{NTOLOGI FALLS??!}

Ed. note: The following is contributed by Mr. Rashidi Kitopeni and Mr. Moshi Bunengwa Kasagula, Tanzanian field assistants at the Kansyana Research Station in Mahale Mts. National Park (with the help of Linda Turner, Kyoto University). The social relationships among Ntologi and his rivals during the past few years before this incident are described on pp.10-11 by $\mathrm{KH}$.

During the late rainy season months of 1995 the availability of fruit in the habitat decreased and M Group chimpanzees were sometimes difficult to observe as they ranged and foraged in small subgroups. So in the month of April when we again began to see relatively large groups which included the alpha male Ntologi and a number of other adult males we were quite happy! When the chimps encountered a troop of red colobus monkeys on 14 April in one of the densely-forested river valleys the excitement and the tension began to mount. The chimps climbed into the trees and the air was filled with alarm calls and the crashing of branches as the monkeys attempted to flee the area. Suddenly we saw two large male chimps fighting and falling through the branches of a tree. We were surprised to see the alpha male, Ntologi, forced to the ground by his younger rival Nsaba. We had noticed over several months that although the relationship between the two males was typically one of two rivals, lately Nsaba had been spending more time near Ntologi, travelling and feeding nearby and even grooming and sitting with him. Had Nsaba perhaps been trying to win Ntologi's trust while gaining the confidence 
to attack him? Now he showed no fear as Ntologi climbed back into the tree. The alpha male was again forced to the ground and appeared to be seriously injured. His left eye was badly lacerated and he seemed to be in pain, repeatedly covering the eye with one hand and holding his head. He climbed into a tree and joined two of his supporters, the younger adult males Toshibo and Aji. One of them had managed to capture a colobus monkey and they seemed to pay little attention to Ntologi as they concentrated on eating the meat. Nsaba lay on the ground a few meters from the tree in which the three males were sitting. When he suddently rose to his feet and approached the tree directly, Ntologi quickly descended and hurried to meet him while vigorously pantgrunting. We lost Ntologi that evening when the chimps hunted again shortly before they made their nests and were unable to find him for a few days. He reappeared again on 19 April and although the day began peacefully he and Nsaba fought again in the afternoon. Ntologi disappeared again and was not seen until 18 May when his status in the group was unclear. His eye injury appeared to be healing well. Ntologi has been the undisputed alpha male of $M$ Group almost continuously since he gained power in 1979. What will happen to him now? We hope to have further news about his fate before long. 